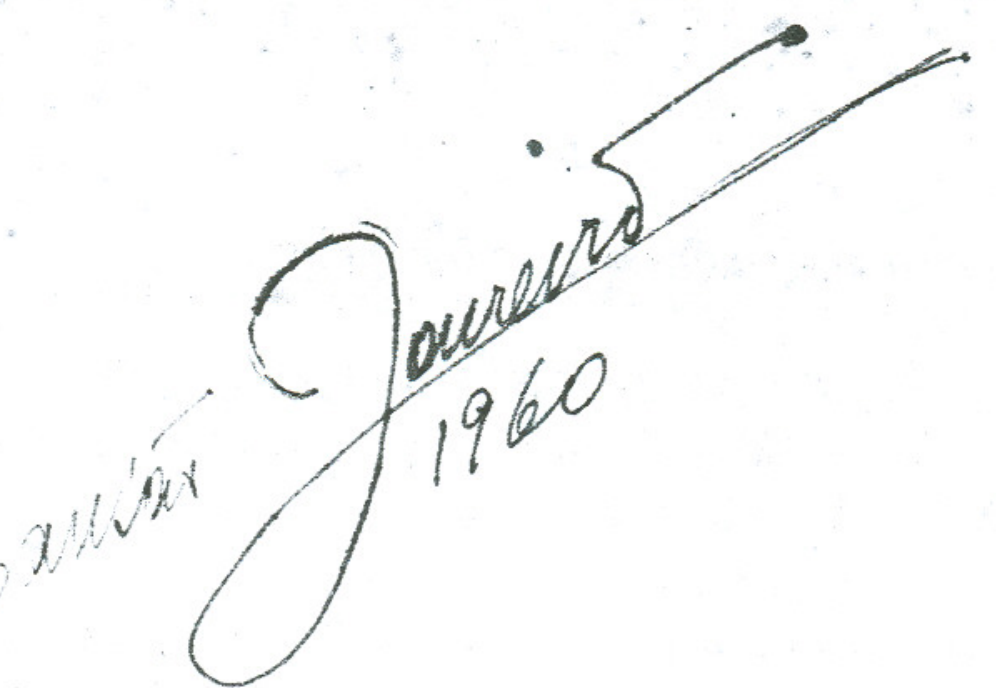

\title{
A EXTINÇÃO DAS AÇÕES AO PORTADOR
}

\author{
Rubens Requião \\ Docente livre de Direito Comercial da Faculdade \\ de Direito da Universidade do Paraná
}

$1 .^{\circ}$ A forma das ações ao portador, contrapondo-se às nominativas, constitui um dos pontos altos a que atingiu o direito comercial e uma das mais expressivas conquistas da economia moderna, na fase capitalista. As vantagens e conveniências do anonimato as difundiram largamente.

O principio de que o simples detentor se presume dono, por tradição manual, sem qualquer solenidade ou instrumentação, representa, por outro lado, a culminância da histórica tendência do direito mercantil, de postergar dos estilos o formalismo excessivo que o Direito Romano impunha às relações jurídicas, sobretudo nas transmissões da propriedade. Hodiernamente, graças às ações ao portador, valores vultuosos se transmitem de pessôa a pessôa, sem outra solenidade a não ser a tradição do título, sem deixar traço algum.

Êsse instituto está, entretanto, em perigo, ameaçado de extinção.

$2 .^{\circ}$ Os modernos comercialistas se têm preocupado seriamente com o fenômeno atual da invasão do campo do direito comercial pelo direito público. A intervenção do Estado no domínio econômico, sua acentuada vocação socialista nos dias que correm, se aproveita dos tributos no propósito de reduzir o desequilíbrio da repartição da riqueza ou proporcionar capitais de que necessita para seus investimentos. A agravação dos impostos, sobretudo os direitos, constitui a fácil e insidiosa técnica de que o Poder Público constantemente lança mão, sobretudo 
em nosso país, para a realização da política intervencionista e financiamento do desenvolvimento econômico ou a pretexto de cobertura de déficits orçamentários.

Na elaboração tributária a serviço de tal política, contiruamente, sob a égide de autonomia jurídica, o direito fiscal se apossa de institutos mercantís, para distorcê-los, recompô-los, renová-los. Premido pela imposição fiscal nada mais resta, em muitos casos, ao direito comercial senão absorvê-los e consagrá-los.

O fenômeno tem sido observado pelos comercialistas. No VI Congresso Jurídico Nacional, reunido em São Paulo, ao ensejo das festas de seu quarto centenário, embora incidentemente, se chamou a atenção dos juristas que alí debatiam os mais destacados aspectos do moderno direito brasileiro. 0 ilustre professor Waldemar Ferreira reconheceu que o direito privado, sobretudo o direito comercial, "está a padecer constrangimento de suas fronteiras pelas avançadas do direito público". E no mesmo debate o jurista Josefat Marinho, invocando o professor Savatier, salientava a tendência resultante da tutela progressiva do direito público sôbre o direito privado. "É certo, afirmou, que há uma condenação a essa tendência, como o exemplo desenvolvido pelo professor Georges Ripert e também pelo próprio René Savatier, conquanto não seja tão limitado quanto o professor Ripert, que admite a necessidade de conter-se essa tendência a fim de que instituições, que são especìficamente do direito privado, não sejam absorvidas pelo direito público". (Rev. de Direito Mercantil, ano 1955, pg. 28).

0 professor Jean Escarra incisivamente registra o fato, no seu moderno "Manuel de Droit Commercial", onde escreve: “... avec le développement de l'économie dirigée, l'on assiste à une pénétration toujours plus profond du droit public dans le droit commercial, l'Etat se transformant lui même en commer. çant et en industriel", (n. 442, pg. 254, Vol. I), observação que o professor belga Van Ryn corrobora em interessantíssima preleção em seu "Principes de Droit Commercial", principiando por colocar o direito comercial em posição intermediária entre o direito privạdo e o públicọ. 
É essa uma incoercivel tendência do direito moderno, e que de certo modo explica a extinção das ações ao portador.

$3 .{ }^{\circ}$ Conhecido o fenômeno, torna-se mais fácil compreender porque, aos poucos, se vai desfigurando ou extinguindo muitos institutos construidos pelo direito comercial. Hoje não se compreende mais, sobretudo no campo das aplicações práticas do direito mercantil, o estudo de suas instituições fora das vistas do direito tributário. Essa circunstância é muito visível no "Tratado de Derecho Mercantil" do professor madrileno Joaquin Garrigues, que a par dos institutos comerciais aborda o correspondente problema tributário.

E na mesma ordem de raciocínio, explica-se a grande voga das sociedades anônimas em nosso país pelas conveniências de ordem tributária que tais entidades proporcionam, face ao sistema impositivo adotado pela legislação do impôsto de renda.

4. ${ }^{\circ}$ Assim, não causa espécie, a pretensão do Poder Executive de extinguir de nosso direito as ações ao portador das sociedades por ações, através de preceito inserto em projeto de lei modificadora da lei do impôsto de renda.

Ns últimos tempos se vem acentuando as investidas do poder público, agravando sucessivamente a incidência sôbre o rendimento das ações ao portador, a ponto de atingir a aliquota vigente de $28 \%$ (art. 96 , alínea $3 .^{\mathrm{a}}$, do dec. 40.702 , de 81-12-1956), a que acresce mais o adicional de $15 \%$ (art. 209, $\left.\S 2 .^{\circ}\right)$. Por fim, em mensagem dirigida ao Congresso Nacional, scb n. ${ }^{\circ} 49 / 1956$, pretende o Poder Executivo, entre outras inovações e alterações do impôsto de renda, a extinção, pura e simples, das ações ao portador.

Êsse Projeto, que tomou o n. ${ }^{\circ}$ 989-A/1956, ainda em tramitação, no art. $8 .^{\circ}$, propõe:

"As ações ao portador que tenham sido emitidas ou subscritas e integralizadas anteriormente até a publicação desta lei, serão convertidas em ações nominativas, dentro do prazo de cinco anos, contados a partir de sua vigência". 
Parágrafo único - Os atos relativos à conversão de ações de que trata este artigo ficam isentos do impôsto do sêlo".

Na mensagem aludida, o então Presidente da República, sr. Nereu Ramos, apresentava a "exposição de motivos" do projeto, redatado no Ministério da Fazenda, na qual se justificava a necessidade da postergação das ações ao portador com esta cadente argumentação: "Um dos casos típicos de evasão tributária consiste em permitir a lei que alguns contribuintes optem pela tributação menor que recai sôbre rendimento de títulos ao portador, fugindo, assim, da justa tabela do impôsto complementar progressivo. Além dêsse grave inconveniente de ordem fiscal, o anonimato dos títulos ao portador, proporciona também ótimo refúgio sob o qual se abrigam sonegações de outros tributos e fortunas ilicitamente adquiridas". No relatório do ano de 1949, o Ministro da Fazenda, a propósito, se manifestava: "O intervencionismo econômico e financeiro do Estado que é determinado pela complexidade da atual estrutura econômica e social está prevista na Constituição. Não se concebe, portanto, que, em virtude de sofismas e asserções desmentidas pela experiência, se continue a conceder aos títulos ao portador, em matéria tributária, privilégios nocivos à coletividade, uma vez que garantem a um grupo de contribuintes em detrimento dos demais a evasão ilícita de vários impostos"... "A não tributação progressiva dos rendimentos de títulos ao portador, conclue o tópico da mensagem, transforma o princípio da capacidade contributiva em uma caricatura de justiça social, pois vai benificiar justamente os contribuintes com maior poder econômico".

5..$^{\circ}$ São bem definidas, como se vê, as razões que ditaram a mensagem governamental, condenando as acões ao portador. Circunscrevem-se as razões oficiais aos motivos de justiça fiscal e justiça social, ficando esquecidas as virtudes que tais títulos possuem na mobilização de valores privados.

A pretensão do projeto, entretanto, não teve boa acolhida no Poder Legislativa. Mas não se pode esquecer que sôbre o problema estão esboçados os contornos de luta política, pois al- 
gumas agremiações partidárias, de sentido populista e de esquerda, têm expressado, como linha programática, o combate à permanência das ações ao portador em nosso direito positivo.

o importante a registrar, todavia, é que na discussão do projeto na Comissão de Economia da Câmara dos Deputados está vencendo a corrente protetora do anonimato, pois em Substitutivo alí apresentado se desconhece a pretendida extinção. O parecer do relator, deputado Draut Ernani, foi radicalmente contrário, defendendo logo de início a autonomia do direito comercial, com a observação: "O primeiro trabalho, oferecido a exame, incluia, na legislação do impôsto de renda, dispositivo proibindo a emissão de títulos ao portador. Seria, a nosso ver, legislar em seara alheia. Trata-se, como sabemos, de assunto que melhor se enquadra na competência da legislação básica das sociedades por ações".

Menos feliz é o parecer quando procura enfrentar o mérito do projeto. Invoca razões de conveniência econômica, acenando com o temor de que tal comportamento legal venha desistimular o ingresso de capitais estrangeiros, de cujas injeções monetárias inquestionavelmente nosso país anda tão necessitado.

Mas o problema da atração de capitais estrangeiros pouca relação tem com a questão em foco. Seria por deveras lamentável que o ingresso de capitais alienígenas se fizesse não pelas garantias de segurança e rentabilidade que a economia nacional deve oferecer, mas pelo engodo de uma proteção fiscal às ações ao portador, que se expressaria numa clara forma de evasão tributária, perniciosa para a vitalidade das finanças nacionais. O que importa, no setor das inversões estrangeiras, no âmbito tributário, parece-nos que é a solução da dupla incidência do impôsto de renda a que estão sujeitas, problema diplomático e político que até hoje não foi resolvido, dado os vultosos interêsses financeiros em jôgo.

Para firmar a tese esposada, deslocando o problema do terreno jurídico para o da conveniência política e financeira, o relator da Comissão de Economia traz à colação um antigo pronunciamento do Ministro de Finanças da França, Caillaux, di. 
tado em 1920, que defendia a permanência do anonimato acionário, sob o fundamento de que "a individualização obrigatória sem um severo acôrdo internacional daria origem a uma evasão de capitais, mais deplorável que a fraude que se deseja sustar". Invoca, também, a experiência italiana, naquela época, em que grave crise financeira teria fustigado a economia daquela nação, provocada pela fuga de capitais, acarretando a falência de grandes indústrias e estabelecimentos bancários, o que teria motivado a suspensão da medida dois meses após ter sido decretada.

Sob êsses fudamentos a Comissão técnica argúe a inoportunidade e inconveniência da aprovação do projeto governamental.

$6 .^{\circ}$ Num exame, embora perfunctório da matéria, não podemos deixar de estranhar a completa desatualização da Comissão de Economia.

Quem folhear os escritos estrangeiros especializados, perceberá que o debate está aceso em torno do tema, mas não mais para a sua adoção, porém para a revogação das leis que o instituiram... Não se invoca, na Itália, por exemplo, motivos po. lítico-financeiros, mas estritamente jurídicos, para o restabelecimento do anonimato acionário. $\mathrm{Na}$ verdade, hodiernamente a nominatividade das ações é a regra nos diferentes países da Europa, de tal forma que a legislação brasileira chega a parecer estranha com seu acentuado liberalismo.

Desde o século passado se ensaiava a Itália para adotar a extrema medida legislativa, proscrevendo as ações ao portador. Após algumas tentativas e longos debates doutrinários, em que intervieram os mais eminentes comercialistas, foi extinto o anonimato, pela lei . $^{\circ}$ 96, de 9 de fevereiro de 1942, regulamentada pelo decreto 239 , de 29 de março do mesmo ano. Diante da permanência da aplicação da lei no após guerra, o problema da validade da lei face à nova Constituição, apaixonou a literatura jurídica e financeira, de vez que aqueles diplomas eram considerados de exceção, próprios para vigir numa economia de guerra. 
Uma sociedade comercial, porisso, reproduziu em seus estatutos o preceito do art. 2355 , do Código Civil unificado, que dispunha: "As ações podem ser nominativas ou ao portador a escolha do sócio que dela fôr titular". No ato de homologação da sociedade, segundo exige o mesmo Código, foi arguida a questão da validade do preceito face à lei $n .^{\circ} 96$, de 1942.0 Tribunal, perante o qual foi presente a questão, suspendeu 0 procedimento de homologação, solicitando audiência da Côrte Constitucional, que se pronunciou, a seis de dezembro do ano findo, sôbre a validade da lei que impunha a nominatividade cbrigatória das ações. (Revista della Societá, Ano, II, fasc. 6., dezembro de 1957).

Autores e técnicos italianos, que têm debatido o assunto, procuram prescrutar as intenções do legislador de 1942, e a doutrina na qual teve apoio. Antônio Gelpi, agente de câmbio de Milão, que publica substancioso estudo na "Revista della Socjetá", concluiu que o legislador vizou apenas um melhor contrôle tributário dos portadores da riqueza mobiliária, pois não estendeu o preceito à nominatividade dos títulos públicos. Para êsse autor a intenção oficial teria sido de fundo político-financeiro, isto é, de levar a economia particular a desinteressar-se, da aplicação de seus recursos nas emprêsas privadas, enca. minhando-a para as inversões em títulos públicos e, em segundo lugar, para melhor contrôle da propriedade dos estrangeiros.

O professor Túlio Ascarelli opina noutro sentido, e a nominatividade obrigatória reflete apenas motivos de equidade, sustentando que "òbviamente nenhuma razão - no terreno da justiça fiscal - poderia justificar a exceção dos rendimentos acionários do impôsto complementar progressivo que incide sôbre tôdas as rendas".

Êsse sistema, adotado pela legisislação italiana e que até hoje perdura, exclue simplesmente $o$ anonimato.

7. ${ }^{\circ}$ Outros paises, como a Inglaterra e Estados Unidos, se comportam mais amenamente em relação essa forma de ações. No primeiro desses paises os acionistas são inscritos, $\epsilon$ m determinada época, no registro de sócios da sociedade, rião só 
para se capacitarem ao exercício de voto nas Assembléias, como, - principalmente, para a percepção dos dividendos, que lhes são remetidos domiciliarmente. $\mathrm{O}$ fisco, a qualquer momento, pode examinar o registro de acionistas, a fim de saber, para efeito de contrôle, a quem foram pagos dividendos.

O sistema americano é mais prático. Preserva o anonimato das ações, mas o exclue dos dividendos. Estes são pagos aos portadores da ação, mas o pagamento é identificado. A ação embora ao portador enseja sòmente dividentos nominativos. $O$ professor Boris Bitker, da Universidade de Yale, explica como se processa o contrôle desses pagamentos pelos agentes fazendários ianques: "A sociedade (nacional, estrangeira com sede nos Estados Unidos e estrangeiras sem sede mas com um tesoureiro nos Estados Unidos) deve declarar todo o pagamento de dividendo de dez ou mais dólares ao cidadão ou ao estrangeiro residente; se o contribuinte lançado nos livros sociais das ações (em cujo nome seja comunicado pela sociedade ao fisco) não é o efetivo titular, deve comunicar o nome e enderêço deste ao fisco, pois do contrário responderá pessoalmente por todos os impostos devidos sôbre os dividendos. O Fisco tem o poder de solicitar da sociedade as informações sôbre os pagamentos dos dividendos, independentemente do quantum, embora atualmente tal comunicação deva ser feita sòmente quando importem em mais de seicentos dólares".

Já a França apresentava outro sistema, atualmente revogado. Por uma lei publicada durante a guerra, em 1941, a nominatividade se impunha ou o portador tinha que obrigatòriamente depositar a ação em bancos ou nas mãos de agentes de câmbio. Foi criada a Caixa Central de Depósito e de Conversão de Títulos - C. C. D. V. T. - que recebia o depósito das ações tefetuadas nos Bancos ou nas mãos dos agentes de câmbio. Muito combatido, êsse sistema foi revogado em 1949, tornando-se facultativo o depósito na SICOVAM (Sociedade Interprofissioral de Compensação dos Valores Mobiliários), denominação que rebatizou a antiga Caixa Central. Um comentarista escreveu que o regime é quasi idêntico ao anterior, mas se tornou facultativo, e jocosamente acrescentou: "como acontece mui- 
tas vêzes na França, a maioria dos que protestavam com a maior indignação contra o regime do depósito quando era obrigatório, a êle permaneceram fieis quando se tornou facultativo! Pode-se dizer que na França, atualmente, para as ações cotadas em Bolsa, a metade está na SICOVAM, um quarto são nominativas, um quarto sòmente em títulos ao portador materialmente livres".

8. $\quad$ O anonimato das ações, como resulta dessa ligeira incursão no direito estrangeiro, está sendo banido. Acentua-se, cada vez mais, a nominatividade obrigatória.

Diante das considerações apresentadas, pode-se classificar em duas categorias os motivos determinantes da extinção das ações ao portador: os de ordem doutrinária e os de ordem político-financeiros.

Doutrinàriamente, a medida é recomendada por motivos de justiça fiscal e social. Não se justificaria tratamento distinto entre os contribuintes. É o ponto de vista adotado pelas autoridades fazendárias brasileiras, nos têrmos da mensagem governamental n. ${ }^{0} 49 / 1956$, e que tem a seu favor a opinião de ilustres juristas do porte de Túlio Ascarelli e, entre nós, do prof.Aliomar Baleeiro.

$\mathrm{Na}$ verdade, o anonimato proporciona um excepcional tratamento tributário para os acionistas, entre os quais citamos os seguintes:

a) - imunidade fiscal do ágio relativo à venda da ação acima do valor nominal;

b) - imunidade absoluta do impôsto estadual de transmissão "causa mortis";

c) - favorecimento dos grandes acionistas, pela limitação da incidência do impôsto de renda na fonte, sem repercussão na declaração do impôsto complementar progressivo da pessôa física.

Com efeito, o anonimato em nosso país exclue da incidência progressiva os altos rendimentos dessas ações, pelo fato de 
que a legislação fiscal limita em $28 \%$ e mais o adicional de $15 \%$ a incidência, na fonte, dos dividendos dos títulos ao portador. Não fôsse êsse privilégio que gozam as ações ao portador, os acionistas sofreriam uma forte incidência, que poderia atingir até cincoenta por cento no caso de dividendos superiores a três milhões de cruzeiros. O fisco estadual nada arrecada por ocasião da sucessão causa mortis dêsse tipo de acionista, o mesmo ocorrendo em relação à negociação das mesmas ações anônimas.

Não encontramos explicação para êsse privilégio tributário. E não vemos, no sistema brasileiro, sua permanência, senão por motivos de tradicionalismo legal.

0 pretexto de que o anonimato incrementa a inversão de capitais, não nos parece procedente. Uma grande massa de acionistas, que aplica o produto de sua poupança em ações, deve preferir a nominatividade, pois que ser-lhes-ia maléfica e desistimulante a aliquota específica do impôsto de renda incidente sôbre os dividendos das ações ao portador. Para a economia individual e média a repercussão do rendimento do capital, invertido em sociedades por ações, na incidência complementar progressiva, dificilmente atingiria aquela alta aliquota.

Não se explica, também, como estímulo às inversões de capitais estrangeiros na economia nacional, porque, então, teriamos assistido, de há muito, expressiva evasão de capitais da Itália, França, Inglaterra e Estados Unidos, em virtude da extinção do anonimato acionário ou do anonimato dos divendos, que procurariam os privilégios que o fisco brasileiro oferece até o presente...

$9 .^{\circ}$ Os motivos de ordem político-financeiros que poderiam determinar a extinção das ações ao portador podem ser indicados no desejo do Estado de exercer maior contrôle sôbre a propriedade de estrangeiros, de desviar para a aplicação de títulos públicos as disponibilidades do produto da poupaça nacional ou incrementar mecanicamente a arrecadação tributária.

Evidentemente as duas primeiras razões são ponderáveis. Mas forçoso é reconhecer que não foi por essas razões que o govêrno propôs a extinção. Nenhum plano financeiro teve co- 
nexão com o projeto. Aliás, os juros de títulos ao portador das dívidas públicas, sejam federais, estaduais ou municipais, sofrem diminuta incidência de $6 \%$ na fonte. Esse excepcional tratamento fiscal, face ao privilégio das ações ao portador $(28 \%$ mais $15 \%$ adicionais), deveria acarretar a absorção dos capitais disponíveis em títulos oficiais e não em sociedades comerciais privadas... Essa consideração nos leva a compreender que a aplicação de capitais não se cínge às vantagens e conveniências tributárias, pelo menos de forma proponderante.

Da eliminação dêsses dois motivos, nos resta o último: o incremento da receita pública. Não há dúvida de que o Poder Executivo, com a proposta encaminhada ao Parlamento Nacional, pretende aumentar a área de incidência do impôsto de renda, atingindo os altos rendimentos dos detentores de ações ao portador em alto volume. Se efetivamente fôssem as preocupações de equidade, de justiça social e fiscal os móveis do projeto de extinção do anonimato, o mesmo princípio haveria de prevalecer em relação aos títulos ao portador da dívida pública, pois nada justificaria a permanência dêsse privilégio. 